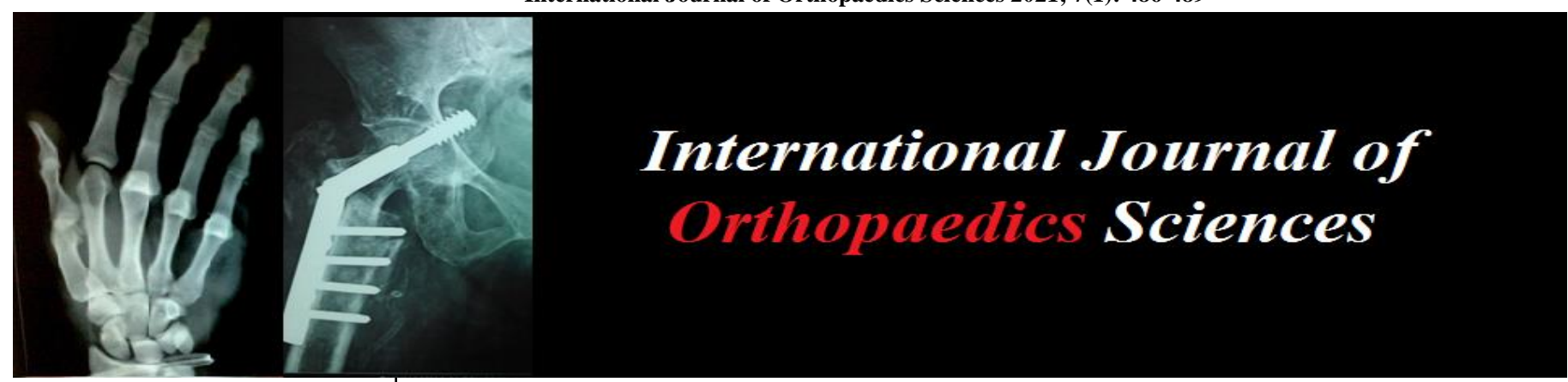

E-ISSN: 2395-1958

P-ISSN: 2706-6630

IJOS 2021; 7(1): 486-489

(C) 2021 IJOS

www.orthopaper.com

Received: 25-11-2020

Accepted: 27-12-2020

\section{Dr. Naveen BS and}

Senior Resident, Department of Orthopedics, MVJ Medical College and Research Hospital, Bangalore, Karnataka, India

\section{Dr. Hemanth R}

Assistant Professor, Department of Orthopedics, MVJ Medical College and Research Hospital, Bangalore, Karnataka, India
Corresponding Author:

\section{Dr. Hemanth R}

Assistant Professor, Department of Orthopedics, MVJ Medical College and Research Hospital, Bangalore, Karnataka, India

\section{Correlates of functional outcome of primary uncemented total hip arthroplasty}

\section{Dr. Naveen BS and Dr. Hemanth R}

DOI: https://doi.org/10.22271/ortho.2021.v7.i1h.2531

\section{Abstract}

Total hip arthroplasty evolved as a result of many improvements of designs of components, availability of suitable component materials and manufacturing techniques. To contend successfully with the many problems that occur and to evaluate new concepts and implants, a working knowledge of biomechanical principles, materials, and design also is necessary. The metal-on-polyethylene articulation remains the standard in total hip arthroplasty. All the patients were contacted for clinical and radiological assessment through postal and personal communication. All 22 patients attended the review arthritis clinic on a previously provided appointment date. The diagnosis, preoperative assessment, operation records and follow up radiographs of these patients were systematically reviewed from the available hospital data. There was no statistical significance in the final outcome with relation to age, sex, laterality, femoral stem size, acetabular cup size or for acetabular inclination angle.

Keywords: total hip arthroplasty, acetabular inclination angle, acetabular cup size

\section{Introduction}

The hip joint is a multiaxial synovial joint of ball-and-socket (spheroidal, cotyloid) type. The femoral head articulates with the cup-shaped (cotyloid) acetabulum, its centre lying a little below the middle third of the inguinal ligament. (The profile of the anterior margin of the joint is parallel to the middle third of the inguinal ligament.) The articular surfaces are reciprocally curved but neither coextensive nor completely congruent.

The femoral head is covered by articular cartilage, except for a rough pit for the ligamentum teres. In front the cartilage extends laterally over a small area on the adjoining neck; it is thickest centrally. Cartilage thickness is maximal anterosuperiorly in the acetabulum and anterolaterally on the femoral head ${ }^{[1]}$. The acetabular articular surface is an incomplete ring, the lunate surface, broadest above where the pressure of body weight falls in the erect posture, and narrowest in its pubic region. It is deficient inferiorly opposite the acetabular notch and covered by articular cartilage, which is thickest where the surface is broadest. The acetabular fossa within it is devoid of cartilage but contains fibroelastic fat largely covered by synovial membrane. Acetabular depth is increased by the acetabular labrum, a fibrocartilaginous rim attached to the acetabular margin. This deepens the cup and bridges the acetabular notch as the transverse acetabular ligament ${ }^{[2]}$. The labrum is triangular in section, attaching by the base of the triangle to the acetabular rim while the apex is its free margin. The diameter of the acetabular cavity is constricted by the labral rim, which embraces the femoral head, maintaining joint stability both as a static restraint and by providing proprioceptive information ${ }^{[3]}$.

A basic knowledge of the biomechanics of the hip and of total hip arthroplasty is necessary to perform the procedure properly, to manage the problems that may arise during and after surgery successfully, to select the components intelligently, and to counsel patients concerning their physical activities ${ }^{[4]}$. The biomechanics of hip function may be described through reference to the kinematics or the kinetics of the hip joint or its prosthetic replacement. Joint kinematics is the description of the angular or translational motion of the joint in response to applied forces; kinetics refers to the forces and moments acting on the joint during motion, whether they arise from muscle activity, inertia, ligamentous restraints, or contact between the femur and pelvis and adjacent structures. 
Total hip components must withstand many years of cyclic loading equal to at least three to five times the body weight, and at times they can be subjected to overloads of 10 to 12 times the body weight ${ }^{[5]}$.

Total hip arthroplasty evolved as a result of many improvements of designs of components, availability of suitable component materials and manufacturing techniques. To contend successfully with the many problems that occur and to evaluate new concepts and implants, a working knowledge of biomechanical principles, materials, and design also is necessary. The metal-on-polyethylene articulation remains the standard in total hip arthroplasty ${ }^{[6]}$. The metals used in total joint implants has evolved from Charnley's original stainless steel to stronger alloys based on either cobalt ortitanium. The metallic implants should be biocompatible and should not produce any inflammatory, allergic or systemic reactions.

\section{Methodology}

\section{Inclusion criteria}

- Patients in the age group between 40-70 years

- Suffering from hip arthritis unilateral or bilateral who were treated with primary uncemented total hip arthroplasty

\section{Exclusion Criteria}

- Patients who had previous surgery(s) of the involved hip

- Patients with associated co morbid conditions such as diabetes mellitus, cardiac diseases, renal and respiratory problems

All these patients were available during the time of our study. All the patients were contacted for clinical and radiological assessment through postal and personal communication. All 22 patients attended the review arthritis clinic on a previously provided appointment date. The diagnosis, preoperative assessment, operation records and follow up radiographs of these patients were systematically reviewed from the available hospital data.

During this clinical assessment, patient's identity was verified and confirmed. The follow-up records of clinical assessment by assessment of pain and activity restriction were done with the questionnaire as per the study proforma and also modified Harris hip score was evaluated at the same setting.

All the patients were operated by the same surgical team headed by the same senior arthroplasty surgeon. 8 patients underwent staged bilateral hip replacement surgery and 14 patients underwent unilateral surgery.

Radiological assessment was done with radiographs of anteroposterior and frog leg lateral views of pelvis with hip joints including entire proximal femur till the tip of the femoral prosthesis. These radiographs were assessed for component placement, inclination, coverage and migration on acetabular side were particularly noted, osteolysis was looked for according to the system of DeLee and Charnley. On the femoral side component placement, subsidence of prosthesis, migration, radiolucent lines and stress-shielding were classified according to the system of Gruen et al. on the femoral side. All radiographs were analyzed for zones of osteolysis as defined by Zicat et al. The stability of the femoral implant was classified according to the system of Engh et al. Heterotopic bone formation was graded according to the criteria of Brooker et al. Linear polyethylene wear was evaluated in two dimensions on anteroposterior radiographs with use of the method described by Charnley and Halley.

Definite loosening of the acetabular component was diagnosed when there was a change in position of the component ( $>2 \mathrm{~mm}$ vertically and/or medially or laterally) or a continuous radiolucent line wider than $2 \mathrm{~mm}$ on both the anteroposterior and lateral radiographs.

Osteolysis was defined if areas of endosteal, intracortical, or cancellous destruction of bone that were not linear, were greater than $2 \mathrm{~mm}$ in width, and had been progressive. Inclination of the cup was measured as the angle between the interteardrop line and a line drawn from the cranial and caudal edge of the cup. If the interteardrop line was not clearly visible, then a line connecting the ischial tuberosities was used as the horizontal reference line.

All patients were subjected to standard clinical, laboratory and radiological evaluation which included brief information about patient age, sex, address, occupation, complaints, clinical history, and associated medical illness.

All the patients were evaluated using modified Harris hip score in terms of pain, ROM, deformities and function. Also limb length discrepancy, Trendelenberg test, ambulatory status of the patient, vascularity of the limb, sensory motor examination, examination of spine, opposite hip and both knees were assessed.

Any infection in the body such as skin lesions, dental caries and urinary tract infections were treated preoperatively.

Radiological assessment: Anteroposterior radiograph of pelvis with proximal femur, lateral view of hip and radiographs of spine were taken in all cases. Radiographs were evaluated for confirmation of diagnosis and to know the anatomical relationships of femur and pelvis for accurate restoration of normal hip joint anatomy and its biomechanics. The femoral bone stock, neck, size of medullary canal, limb length discrepancy and acetabular bone stock, periacetabular osteophytes, approximate cup size, structural integrity of acetabulum, any protrusion, floor of the acetabulum and need for bone grafting were evaluated.

Templating was done for femoral and acetabular components. On the femoral side, appropriate neck length, offset, stem size were chosen and on acetabular side appropriate acetabular cup size and anteversion were determined.

\section{Results}

Table 1: Effect of clinical variables on final outcome

\begin{tabular}{|c|c|c|c|}
\hline \multirow{2}{*}{ Clinical variables } & \multicolumn{3}{|c|}{ Modified Harris hip score } \\
\cline { 2 - 4 } & Pre-op & Post-op & Difference \\
\hline \multicolumn{4}{|c|}{ Age in years } \\
\hline $40-50$ & $36.86 \pm 6.18$ & $92.43 \pm 1.81$ & $55.57 \pm 5.5$ \\
\hline $51-60$ & $37.79 \pm 8.24$ & $90.32 \pm 6.17$ & $52.53 \pm 7.88$ \\
\hline $61-70$ & $36.75 \pm 3.59$ & $94.25 \pm 3.4$ & $57.5 \pm 6.4$ \\
\hline P value & 0.942 & 0.337 & 0.375 \\
\hline \multicolumn{4}{|c|}{ Gender } \\
\hline Male & $38.22 \pm 7.93$ & $90.74 \pm 5.66$ & $52.52 \pm 7.51$ \\
\hline & $\sim 487 \sim$ \\
\hline
\end{tabular}




\begin{tabular}{|c|c|c|c|}
\hline Female & $34.86 \pm 2.97$ & $93.29 \pm 3.25$ & $58.43 \pm 4.12$ \\
\hline $\mathrm{P}$ value & 0.286 & 0.269 & $0.058+$ \\
\hline \multicolumn{4}{|c|}{ Laterality } \\
\hline Unilateral & $39.07 \pm 8.37$ & $91.50 \pm 5.35$ & $52.43 \pm 8.83$ \\
\hline Bilateral & $36.00 \pm 5.87$ & $91.19 \pm 5.36$ & $55.19 \pm 5.53$ \\
\hline P value & 0.250 & 0.874 & 0.307 \\
\hline \multicolumn{4}{|c|}{ Femoral Stem Size } \\
\hline $9 \mathrm{~mm}$ & $41.00 \pm 9.90$ & $92.50 \pm 3.54$ & $51.50 \pm 13.44$ \\
\hline $10 \mathrm{~mm}$ & $33.50 \pm 5.32$ & $91.00 \pm 2.45$ & $57.50 \pm 4.04$ \\
\hline $11 \mathrm{~mm}$ & $35.13 \pm 6.24$ & $91.50 \pm 7.39$ & $56.38 \pm 6.19$ \\
\hline $12 \mathrm{~mm}$ & $40.38 \pm 9.75$ & $91.00 \pm 5.18$ & $50.63 \pm 9.10$ \\
\hline $13 \mathrm{~mm}$ & $37.25 \pm 3.40$ & $89.00 \pm 6.16$ & $51.75 \pm 8.06$ \\
\hline $14 \mathrm{~mm}$ & $37.00 \pm 0.00$ & $92.50 \pm 0.71$ & $55.50 \pm 0.71$ \\
\hline $15 \mathrm{~mm}$ & $40.00 \pm 11.31$ & $95.00 \pm 5.66$ & $55.00 \pm 5.66$ \\
\hline$P$ value & 0.701 & 0.938 & 0.683 \\
\hline \multicolumn{4}{|c|}{ Acetabular size } \\
\hline $48 \mathrm{~mm}$ & $36.50 \pm 3.54$ & $94.50 \pm 0.71$ & $58.00 \pm 4.24$ \\
\hline $50 \mathrm{~mm}$ & $30.00 \pm 2.83$ & $95.00 \pm 5.66$ & $65.00 \pm 2.83$ \\
\hline $52 \mathrm{~mm}$ & $36.62 \pm 7.72$ & $89.69 \pm 5.78$ & $53.08 \pm 8.04$ \\
\hline $54 \mathrm{~mm}$ & $39.29 \pm 6.40$ & $91.14 \pm 5.87$ & $51.86 \pm 5.18$ \\
\hline $56 \mathrm{~mm}$ & $41.00 \pm 8.19$ & $93.00 \pm 5.29$ & $52.00 \pm 6.56$ \\
\hline $58 \mathrm{~mm}$ & $33.00 \pm 1.41$ & $92.00 \pm 2.83$ & $59.00 \pm 1.41$ \\
\hline $60 \mathrm{~mm}$ & $50.00 \pm 0.00$ & $94.00 \pm 0.00$ & $44.00 \pm 0.00$ \\
\hline $\mathrm{P}$ value & 0.294 & 0.775 & 0.155 \\
\hline \multicolumn{4}{|c|}{ Acetabular Angle } \\
\hline 40 & $37.83 \pm 5.65$ & $93.00 \pm 2.41$ & $55.17 \pm 5.18$ \\
\hline 45 & $31.00 \pm 2.65$ & $85.00 \pm 8.66$ & $54.00 \pm 6.08$ \\
\hline 50 & $36.00 \pm 4.94$ & $90.33 \pm 6.41$ & $54.33 \pm 9.81$ \\
\hline 52 & $41.67 \pm 11.93$ & $94.33 \pm 3.51$ & $52.67 \pm 9.61$ \\
\hline 55 & $39.17 \pm 10.15$ & $90.67 \pm 5.82$ & $51.5 \pm 9.31$ \\
\hline$P$ value & 0.416 & 0.137 & 0.905 \\
\hline
\end{tabular}

There was no statistical significance in the final outcome with relation to age, sex, laterality, femoral stem size, acetabular cup size or for acetabular inclination angle.

Table 2: Effect of indication of surgery on final outcome

\begin{tabular}{|c|c|c|c|}
\hline \multirow{2}{*}{ Indication of surgery } & \multicolumn{3}{|c|}{ Modified Harris hip score } \\
\cline { 2 - 4 } & Pre-op & Post-op & Difference \\
\hline Secondary OA due to AVN of femoral head & $37.1 \pm 7.2$ & $91.95 \pm 4.95$ & $54.86 \pm 7.32$ \\
\hline Others & $38.22 \pm 7.53$ & $89.89 \pm 5.97$ & $51.67 \pm 7$ \\
\hline Total & $37.43 \pm 7.19$ & $91.33 \pm 5.26$ & $53.9 \pm 7.26$ \\
\hline P value & 0.701 & 0.334 & 0.270 \\
\hline
\end{tabular}

We did not find any statistical significance between the indications of the surgery to the final outcome in terms of modified Harris hip score.

\section{Discussion}

Our study included new generation prosthesis (hydroxyapatite coated proximal fitting femoral stem with metal backed porous coated acetabular shell) when inserted in the exact manner has produced the excellent to good results. This shows better osteointegration with modern versions of prosthesis than the earlier versions. We used corail stem in all hips. This stem has long stem survival, including $97 \%$ survivorship in 5456 cases at 15 years by Hallan G et al. ${ }^{[7]}$.

Another factor that may be of importance in determining the outcome of arthroplasties without cement is selection of patients. Rheumatoid arthritis, avascular necrosis or congenital hip dysplasia may influence the biological integration of the implant and bone remodelling [8], thereby affecting the overall outcome. In our study we found that there was statistically significance between the indication of the surgery and the final outcome.

Konyves and Bannister ${ }^{[9]}$ noted that lengthened were also associated with lower clinical hip scores. Limb length discrepancy can result from a poor preoperative patient evaluation as well as intraoperative technical errors with regard to the level of the resection of the femoral neck, the prosthetic neck length or the failure to restore the offset. In our study 4 patients had limb length discrepancy, all of them showed excellent results in their final outcome.

Bourne R B et al. ${ }^{[10]}$ studied 101 total hip replacements with porous coated anatomic prosthesis, reported pain in the thigh in $27 \%$ and more than 2 milimetres of subsidence of femoral stem in twenty five hips. In our study, we did not have any cases of subsidence of implant.

Anterior thigh pain occurred in 3 patients (13.63\%) which disappeared after few months. Callaghan et al. ${ }^{8}$ reported that $18 \%$ had pain in the thigh occurred at 1 year of follow up and $16 \%$ had pain in the thigh after two years of follow up with the use of porous coated anatomic stem. Heekin et al. [11] reported $15 \%$ of anterior thigh pain in 91 hips at five years of follow up study. Thus our study is comparable with the above studies.

Two hips developed postoperatively nerve injury in the form of foot drop $(6.66 \%)$ which recovered gradually over a period of 6-8 months in both the patients which was comparable with the study by Gabriel D Brown et al. ${ }^{[12]}$ where the incidence ranges from 0.08 to $7.6 \%$. One patient (4.54\%) had asymptomatic aseptic loosening of acetabular component and 
has been advised to follow up regularly, final outcome was not affected which is comparable with the study by B K Dhoan et al. where one patient in their had the same complication. One patient $(4.54 \%)$ developed Brooker grade 2 heterotopic ossification without limitation of movements which is comparable with the study by B K Dhoan et al. who had one patient with heterotopic ossification out of 47 hips.

\section{Conclusion}

The outcome of uncemented total hip arthroplasty is determined by multiple factors, including the selection of the patients, design of the components and operative techniques. The results of the must be evaluated in long term studies, in our study suggests that current generation of implants without cement can provide satisfactory clinical and functional outcomes after an intermediate duration of follow up.

\section{References}

1. Clohisy JC, Harris WH. The Harris-Galante porouscoated acetabular component with screw fixation: An average ten-year follow-up study. J Bone Joint Surg [Am] 1999;81-A:66-73.

2. Collier JP, Mayor MB, Chae JC et al. Macroscopic and microscopic evidence of prosthetic fixation with porouscoated materials. Clin Orthop Relat Res 1988;235:173180.

3. Cook SD, Barrack RL, Thomas KA, Haddad RJ Jr. Quantitative analysis of tissue growth into human porous total hip components. J Arthroplasty 1988;3:249-262.

4. Angadi DS, Brown S, Crawfurd EJP. Cemented polyethylene and cementless porous-coated acetabular components have similar outcomes at a mean of seven years after total hip replacement. J Bone Joint Surg Br 2012; 94-B:1604-10.

5. Ng CY, Ballantyne JA, Brenkel IJ. Quality of life and functional outcome after primary total hip replacement A 5 year follow up study. Bone Joint Surg [Br] 2007;89B:868-73.

6. Alexander C, Gordon Darry, D'Lima D, Clifford W, Colwell Jr. Highly Cross- linked Polyethylene in Total Hip Arthroplasty. J Am Acad Orthop Surg 2006;14:511523.

7. Hallan G, Lie SA, Furnes O, Engesaeter LB, Vollset SE, Havelin LI, et al. Medium- and long-term performance of 11516 uncemented primary femoral stems from the Norwegian arthroplasty register. J Bone Joint Surg [Br] 2007;89-B:1574-80.

8. Heekin RD, Callaghan JJ, Hopkinson WJ, Savory CJ, Xenos JS. The porous coated anatomic total hip prosthesis, inserted without cement. Results after five to seven year follow up prospective study. J Bone and Joint surgery 1993;75-A:77-91.

9. Konyves A, Bannister GC. The importance of leg length discrepancy after total hip arthroplasty. J Bone Joint Sur Br 2005;87:155-7.

10. Bourne RB, Rorabeck CH, Ghazal ME, Lee MH. Pain in the thigh following total hip replacement with a porous coated anatomic prosthesis for osteoarthrosis: A five-year follow-up study. J Bone Joint Surg Am 1994;76:14641470.

11. Heekin RD, Callaghan JJ, Hopkinson WJ, Savory CJ, Xenos JS. The porous coated anatomic total hip prosthesis, inserted without cement. Results after five to seven year follow up prospective study. J Bone and Joint surgery 1993;75-A:77-91.
12. Gabriel D Brown MD, Eli A Swanson MD, Ohannes A Nercessian MD. Neurologic Injuries After Total Hip Arthroplasty. Am J Orthop 2008;37(4):191-197. 